\title{
Article \\ Sulfur-Doped Carbon Nanohorn Bifunctional Electrocatalyst for Water Splitting
}

\author{
Antonia Kagkoura ${ }^{1, *}$, Raul Arenal $2,3,4$ (D) and Nikos Tagmatarchis $1, * \mathbb{C}$ \\ 1 Theoretical and Physical Chemistry Institute, National Hellenic Research Foundation, \\ 48 Vassileos Constantinou Avenue, 11635 Athens, Greece \\ 2 Laboratorio de Microscopias Avanzadas (LMA), Universidad de Zaragoza, Mariano Esquillor s/n, \\ 50018 Zaragoza, Spain; arenal@unizar.es \\ 3 Instituto de Nanociencia y Materiales de Aragon (INMA), CSIC-U, de Zaragoza, Calle Pedro Cerbuna 12, \\ 50009 Zaragoza, Spain \\ 4 ARAID Foundation, 50018 Zaragoza, Spain \\ * Correspondence: akagkoura@eie.gr (A.K.); tagmatar@eie.gr (N.T.)
}

Received: 6 November 2020; Accepted: 1 December 2020; Published: 3 December 2020

\begin{abstract}
Sulfur-doped carbon nanohorns (S-CNHs) were prepared by an easy one-pot solvothermal process and were employed as efficient electrocatalysts towards water splitting. Initially, oxidation of $\mathrm{CNHs}$ followed by thermal treatment with the Lawesson's reagent resulted in the formation of S-CNHs with the sulfur content determined as high as 3\%. The S-CNHs were thoroughly characterized by spectroscopic, thermal and electron microscopy imaging means and then electrocatalytically screened. Specifically, S-CNHs showed excellent activity and durability for both $\mathrm{O}_{2}$ and $\mathrm{H}_{2}$ evolution reactions, by showing low overpotential at 1.63 and $-0.2 \mathrm{~V}$ vs. RHE for oxygen and hydrogen evolution reaction, respectively. Additionally, $\mathrm{S}-\mathrm{CNHs}$ showed significantly lower Tafel slope value and lower current resistance compared to oxidized and pristine $\mathrm{CNHs}$ for both electrocatalytic reactions. The outstanding electrocatalytic properties and high conductivity, along with the high S-doping level, render S-CNHs a promising bifunctional electrocatalyst for water splitting.
\end{abstract}

Keywords: carbon nanohorns; sulfur-doping; electrocatalysis; water-splitting; oxygen evolution reaction; hydrogen evolution reaction

\section{Introduction}

Electrochemical water splitting is a cost-effective clean method for breaking down water to hydrogen $\left(\mathrm{H}_{2}\right)$ and oxygen $\left(\mathrm{O}_{2}\right)$ and is absolutely important in hydrogen economy. In a water electrolyzer, water electrolysis is separated into two half-reactions: hydrogen evolution reaction (HER) happens at the cathode, i.e., $2 \mathrm{H}^{+}+2 \mathrm{e}^{-} \rightarrow \mathrm{H}_{2}$ (under acidic conditions), while oxygen evolution reaction (OER) occurs at the anode, i.e., $2 \mathrm{H}_{2} \mathrm{O} \rightarrow \mathrm{O}_{2}+4 \mathrm{H}^{+}+4 \mathrm{e}^{-}$. Notably, OER is more kinetically sluggish compared to HER, as it is a four-electron transfer reaction, while HER requires only two electrons. To date, both of these half-reactions have relied on noble-metal-based electrocatalysts to reach their best performance, namely $\mathrm{Pt}$ for $\mathrm{HER}$, and $\mathrm{IrO}_{2}$ and $\mathrm{RuO}_{2}$ for OER [1-4]. Despite their high activity, noble-metal-based electrocatalysts are expensive, and this limits their employment in real applications. In this context, progress has been made towards the exploration of non-precious-based metal electrocatalysts, while recent trends want transition metal-based and carbonaceous electrocatalysts to reach low overpotentials for HER and OER [5-13]. Moreover, due to the different mechanisms that govern HER and OER, it is quite often a good electrocatalyst that can perform at lower overpotential for HER to show poor activity for OER and vice versa. Therefore, it still remains quite a challenge to effectively employ highly active, stable, abundant and low-cost bifunctional electrocatalysts for water electrolysis that compete the performance of the precious metals ones $[1,14]$. 
Carbon nanohorns (CNHs) consist of single-graphene tubules, with highly strained conical ends that aggregate in larger spherical superstructures [15-17]. Their unique shape, chemical defects and crystal edges make them interesting material as electrocatalyst $[15,16]$. Specifically, CNHs have mostly been employed as supports, and have shown encouraging results in crucial electrocatalytic reactions involved in fuel cells, assisting in reaching superior performances as well as improved durability and stability [15]. In addition, doping with heteroatoms has proven to be an efficient method for increasing the catalytic activity of graphene-related materials [18-21] and specifically CNHs [22-25]. Nevertheless, effective, easy and inexpensive ways of incorporating heteroatom dopants is still challenging, since doping methods mostly involve tedious and expensive preparation techniques $[15,26,27]$. However, CNHs are still not fully exploited as electrocatalysts, since there are only very few works dealing with CNHs in HER [28,29] and OER [30] and none as bifunctional electrocatalyst for both.

Considering all of the aforementioned points, we embarked on the preparation of sulfur-doped CNHs (S-CNHs) and the subsequent assessment of their electrocatalytic ability. Herein, S-CNHs were prepared by employing a simple and inexpensive one-pot solvothermal method, fully characterized using complementary spectroscopic, thermal and microscopy imaging means, and their bifunctional nature to electrocatalyze the HER and OER was screened. Notably, for the first time, we report data showing excellent electrocatalytic activity and durability of S-CNHs for both HER and OER.

\section{Materials and Methods}

\subsection{Preparation of ox-CNHs}

For the preparation of ox-CNHs, $30 \mathrm{mg}$ of pristine CNHs were treated with $\mathrm{H}_{2} \mathrm{O}_{2}(50 \mathrm{~mL})$ under light irradiation at $120^{\circ} \mathrm{C}$ for $3 \mathrm{~h}$. Then, the dispersion was filtrated through PTFE membrane filter (pore size $0.2 \mu \mathrm{m}$ ), and the solid residue was extensively washed with deionized water and methanol. This procedure was repeated to obtain the ox-CNHs material as black powder.

\subsection{Preparation of S-Doped CNHs}

An amount of $50 \mathrm{mg}$ of ox-CNHs and $250 \mathrm{mg}$ of Lawesson's reagent (St. Louis, MO, USA) were dispersed in $210 \mathrm{~mL}$ of diethylene glycol methyl ether and sonicated for $30 \mathrm{~min}$. Afterwards, the mixture was placed into a $300 \mathrm{~mL}$ Teflon-lined stainless-steel autoclave reactor. The autoclave reactor was kept at $230^{\circ} \mathrm{C}$ for $48 \mathrm{~h}$. The dispersion was filtered over a PTFE filter (pore size $0.2 \mu \mathrm{m}$ ) and washed extensively with methanol. The solid residue was collected to obtain the S-doped CNH material.

\subsection{General}

Chemicals, reagents, and solvents were purchased from Sigma-Aldrich and used without further purification. Infrared (IR) spectra were obtained on a Fourier Transform IR spectrometer (Equinox 55 from Bruker Optics, Billerica, Massachusetts, US) equipped with a single reflection diamond attenuated total reflection (ATR) accessory (DuraSamp1IR II by SensIR Technologies, Danbury, CT, USA). Raman measurements were recorded with a Renishaw confocal spectrometer (Wotton-under-Edge, UK) at $514 \mathrm{~nm}$. The data were obtained and analyzed with Renishaw Wire and Origin software (OriginPro 2018, Northampton, MA, USA). Thermogravimetric analysis was performed using a TGA Q500 V20.2 Build 27 instrument by TA (New Castle, DE, USA) in a nitrogen (purity > 99.999\%) inert atmosphere. High-resolution TEM was performed employing an imaging-side aberration-corrected FEI Titan-Cube microscope working at $80 \mathrm{kV}$, equipped with a Cs corrector (CETCOR from CEOS $\mathrm{GmbH}$, Heidelberg, Germany). XPS were recorded on a Kratos Axis Supra spectrometer, (Manchester, UK) equipped with a monochromated $\mathrm{Al} \mathrm{K} \alpha$ X-ray source using an analyzer pass energy of $160 \mathrm{eV}$ for survey spectra and $20 \mathrm{eV}$ for the core level spectra. Spectra were recorded by setting the instrument to the hybrid lens mode and the slot mode providing approximately a $700 \times 300 \mu \mathrm{m}^{2}$ analysis area using charge neutralization. Regions were calibrated using the reference value $\mathrm{BE}(\mathrm{C} 1 \mathrm{~s} \mathrm{sp} 2)=284.5 \mathrm{eV}$. 
All XPS spectra were analyzed using CASA XPS software (2.3.23, Teignmouth, Devon, UK). The XPS peaks were fitted to GL(70) Voigt lineshape (a combination of 70\% Gaussian and 30\% Lorentzian character), after performing a Shirley background subtraction. For the light-assisted oxidation reaction of $\mathrm{CNHs}$ the light source used was a $500 \mathrm{~W}$ halogen lamp, which was positioned $20 \mathrm{~cm}$ away from the reactor. Autoclave synthesis was undertaken in a Parr autoclave reactor with a $300 \mathrm{~mL}$ Teflon-lined stainless-steel vessel. All electrochemical measurements were carried out using an Metrohm Autolab PGSTAT128N potentiostat/galvanostat and were carried out at room temperature in a standard three-compartment electrochemical cell by using a platinum wire as a counter-electrode, an RDE with glassy carbon disk (geometric surface area: $\left.0.0196 \mathrm{~cm}^{2}\right)$ as a working electrode, and $\mathrm{Hg} / \mathrm{HgSO}_{4}(0.5 \mathrm{M}$ $\left.\mathrm{K}_{2} \mathrm{SO}_{4}\right)$ and $\mathrm{Hg} / \mathrm{HgO}(0.1 \mathrm{M} \mathrm{KOH})$ (AMEL S.r.l., Milan, Italy) as reference electrodes for HER and OER, respectively. LSV measurements for HER were carried out at room temperature in $\mathrm{N}_{2}$-saturated $0.5 \mathrm{M}$ $\mathrm{H}_{2} \mathrm{SO}_{4}$. LSV measurements for OER were carried out at room temperature in $\mathrm{O}_{2}$-saturated $1.0 \mathrm{M} \mathrm{KOH}$. The catalyst ink was prepared by dispersing $4.0 \mathrm{mg}$ of the catalytic powder in a $1 \mathrm{~mL}$ mixture of water, isopropanol, and $5 \%$ Nafion $(v / v / v=4: 1: 0.02)$ and sonicated for $30 \mathrm{~min}$ prior to use. Before casting the electrocatalytic ink on the electrode's surface, the working electrode was polished with 6-, 3- and 1-mm diamond pastes, rinsed with deionized water, and sonicated in double-distilled water. Afterwards, $8.5 \mu \mathrm{L}$ aliquots of the electrocatalyst were casted on the electrode surface and were left to dry at room temperature. Electrochemical Impedance Spectroscopy (EIS) measurements (Metrohm Autolab, Utrecht, The Netherlands)) were conducted from $10^{5}$ to $10^{-1} \mathrm{~Hz}$ with an AC amplitude of $0.01 \mathrm{~V}$, at a potential where significant HER and OER current was recorded, at $-2 \mathrm{~mA} / \mathrm{cm}^{2}$ for HER and at $3 \mathrm{~mA} / \mathrm{cm}^{2}$ for OER. EIS data were fitted to Randles circuit. In EIS fit and simulation Chi square value is $<0.001$. The data were obtained and analyzed with Nova 2.1.4 software (Metrohm Autolab, Utrecht, The Netherlands).

\section{Results and Discussion}

The preparation of S-doped CNHs was accomplished by treatment of oxidized CNHs (ox-CNHs) with Lawesson's reagent, which was used as sulfur source, in the autoclave reactor, as shown in Figure 1. The doping of S atoms occurs mostly at the conical tips of ox-CNHs, where carbonyl groups are abundantly present. The doping mechanism can be briefly described as follows: initially, thioketone groups are formed, and afterwards, $S$ atoms replace $C$ atoms in the graphitic network $[20,21]$. ATR-IR and Raman spectra give proof of the successful realization of S-doped CNHs. Specifically, while the IR spectrum of ox-CNHs is governed by the characteristic carbonyl-related band at $1705 \mathrm{~cm}^{-1}$ due to stretching vibrations of the carboxylic acid moieties, the corresponding IR spectrum due to S-CNHs shows the decrease of the carbonyl band and the evolution of a new broad band at $1080 \mathrm{~cm}^{-1}$ related to C-S vibrations (Figure 2a). On the other hand, the Raman spectrum of pristine CNHs exhibits the characteristic D-band at $1341 \mathrm{~cm}^{-1}$, associated with defects, and the G-band at $1591 \mathrm{~cm}^{-1}$, related to the $\mathrm{sp}^{2}$ graphitic network. In the Raman spectrum of ox-CNHs, an increase of the intensity ratio $\mathrm{I}_{\mathrm{D} / \mathrm{G}}$ compared to pristine CNHs from 1.3 to 1.7 , due to the change of hybridization from $\mathrm{sp}^{2}$ to $\mathrm{sp}^{3}$ upon oxidation, is evident. Concerning S-CNHs, there is a decrease of the $\mathrm{I}_{\mathrm{D} / \mathrm{G}}$ to 1.0 (Figure $2 \mathrm{~b}$ ) due to S-doping and partial restoration of the graphitic network [31]. Additionally, there is a shift of the G-band to lower frequencies by $8 \mathrm{~cm}^{-1}$, which is indicative of n-doping in S-CNHs [20].

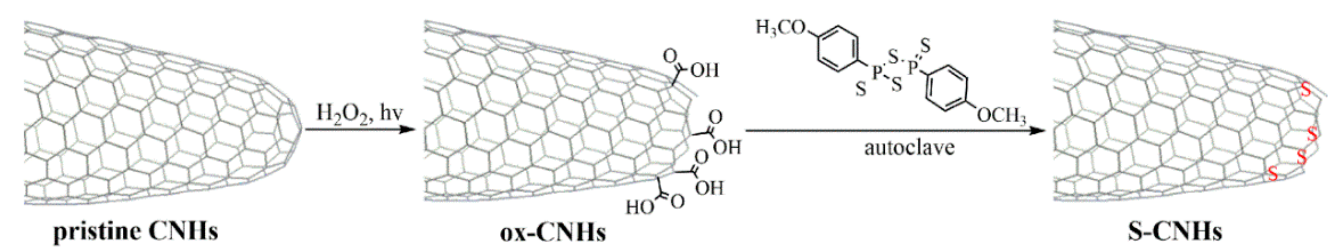

Figure 1. Illustrative preparation of S-CNHs. 

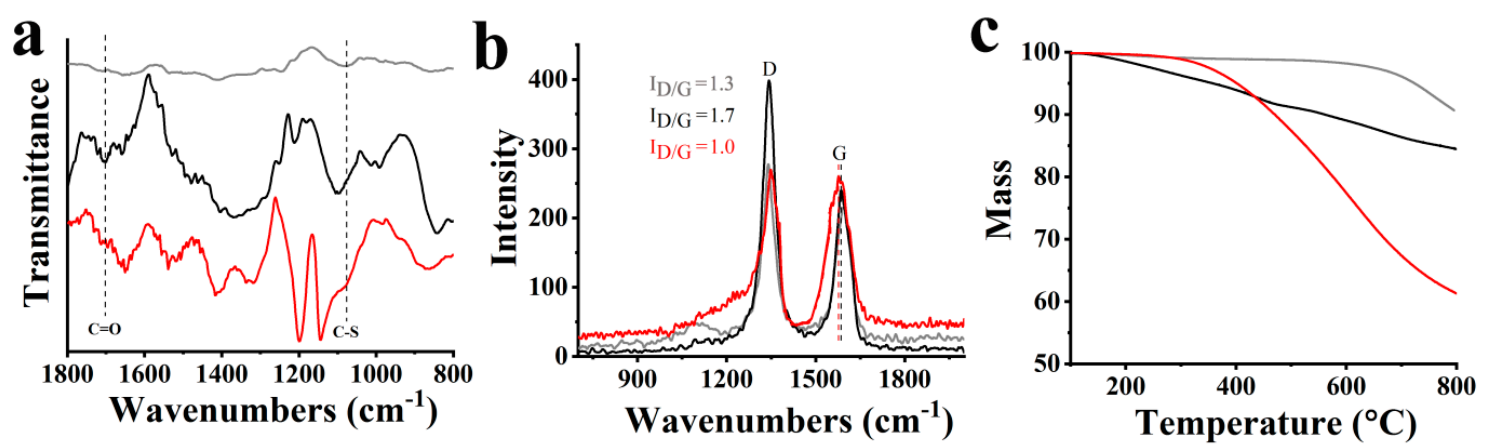

Figure 2. (a) ATR-IR spectra, (b) Raman spectra (514 nm), and (c) thermogravimetric analysis graphs obtained under nitrogen atmosphere of S-CNHs (red), ox-CNHs (black) and pristine CNHs (grey).

Figure 2c shows the thermographs of pristine $\mathrm{CNHs}$, ox-CNHs and $\mathrm{S}-\mathrm{CNH}$ s that were recorded under nitrogen atmosphere. Pristine $\mathrm{CNH}$ present an almost stable thermal profile up to $800{ }^{\circ} \mathrm{C}$, while ox-CNHs show a $9 \%$ mass loss up to $500{ }^{\circ} \mathrm{C}$ due to the thermal decomposition of the carboxylic groups. Conversely, this is not shown in the thermograph of S-CNHs, where the thermal mass loss starts after $330{ }^{\circ} \mathrm{C}$. The mass loss at higher temperatures is attributed to the thermal decomposition of the graphitic framework at $\mathrm{sp}^{3}$ defects close to where sulfur doping takes place.

HR-TEM imaging and XPS were employed to determine the morphology and the chemical composition and elemental content of S-CNHs. In more detail, HR-TEM micrographs (Figure 3a,b) show the characteristic morphology of those nanostructures and their aggregates' organization. In the XPS survey spectrum of S-CNHs, characteristic peaks due to $\mathrm{S}_{2 \mathrm{p}}, \mathrm{C}_{1 \mathrm{~s}}, \mathrm{O}_{1 \mathrm{~s}}$ located at binding energies of ca. 164, 285 and 533, respectively, are evident (Figure 3c). Moreover, the $S$ content was determined to be $3 \%$, higher than that reported for S-doped graphene [31] and previously prepared S-doped CNHs [26]. To probe the chemical state of sulfur in S-CNHs high-resolution $\mathrm{S}_{2 p}$ peaks were analyzed (Figure 3d). The $S_{2 p}$ peaks can be resolved into four peaks at binding energies of $162.2(8.4 \%), 164.1(70.6 \%)$, $165.3(11.3 \%)$ and $168.4(9.8 \%) \mathrm{eV}$, respectively. While the second and third deconvoluted peaks are related to sulfur bound as heteroatoms to aromatics, such as thiophene [31,32], the peaks at 162.2 and $168.4 \mathrm{eV}$ arise from thiol and sulfone components [31,32]. The high percentage of the peaks corresponding to C-S related bonds confirms that doping of sulfur atoms happens mostly at the conical tips of CNHs where five-membered rings are located [16].

Next, evaluating the electrocatalytic properties of S-CNHs against OER, linear sweep voltammetry (LSV) measurements were performed in $\mathrm{O}_{2}$ saturated $1.0 \mathrm{M}$ aqueous $\mathrm{KOH}$. A very important factor for evaluating the performance of OER electrocatalysts is the onset potential. However, since it is hard to determine the exact value, the potential at $10 \mathrm{~mA} / \mathrm{cm}^{2}$ is commonly used as a benchmark. In OER, overpotential is the potential difference between the potential registered at a specific current density and the equilibrium potential, i.e., $1.23 \mathrm{~V}[1,2]$. Figure $4 \mathrm{a}$ screens the polarization curves of S-CNHs, ox-CNHs and pristine CNHs. It is clear from the LSV curves and the recorded values of overpotentials registered at $10 \mathrm{~mA} / \mathrm{cm}^{2}$ current density (Table 1) that S-CNHs possess the best electrocatalytic activity with the lowest potential at $1.63 \mathrm{~V}$ vs. RHE. Such a low overpotential is considered excellent for the OER, and is close to the overpotentials registered for noble metals [1,2,12]. On the contrary, the corresponding potential for both ox-CNHs and pristine $\mathrm{CNHs}$ was registered at 1.82 vs. RHE, $220 \mathrm{mV}$ higher than that of S-CNHs. At the same time, S-CNHs reached high current density values compared to the other two reference materials, which is a prerequisite for an effective OER electrocatalyst. The superior electrocatalytic activity of S-CNHs is attributed to the presence of sulfur dopants, which induce a non-uniform spin density distribution due to the mismatch of the outermost orbitals of sulfur and carbon atoms, while further altering the charge density at nearby sites. 


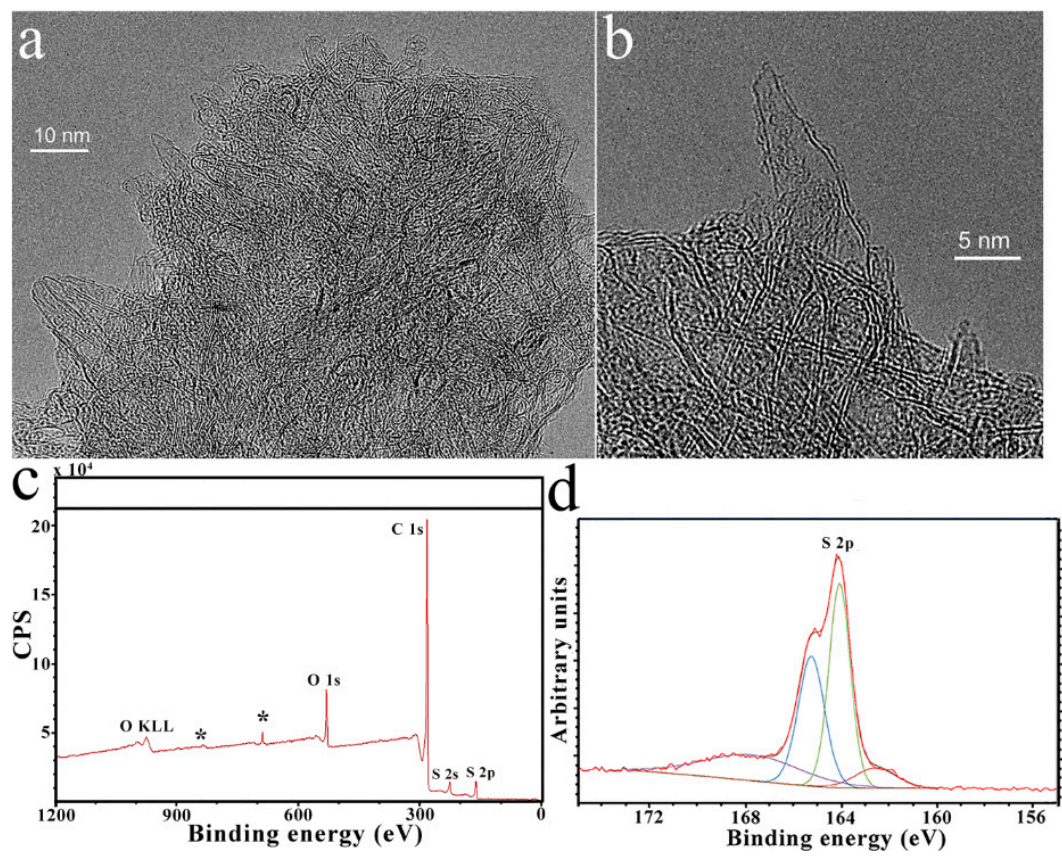

Figure 3. (a,b) HR-TEM micrographs showing the structure of S-CNHs. (c) XPS survey spectrum recorded on one of these $\mathrm{S}-\mathrm{CNH}$ samples, where $\mathrm{S}_{2 \mathrm{p}}, \mathrm{C}_{1 \mathrm{~s}}$ and $\mathrm{O}_{1 \mathrm{~s}}$ are observed. Impurities $<1 \%$ due to $\mathrm{F}$ are shown with *. (d) High-resolution $\mathrm{S}_{2 \mathrm{p}}$ XPS of S-CNHs. The peaks are fitted to four components centered at 162.2, 164.1, 165.3 and 168.4, corresponding to $\mathrm{S}_{\mathrm{p} 3 / 2}, \mathrm{~S}_{\mathrm{p} 3 / 2}, \mathrm{~S}_{\mathrm{p} 1 / 2}$, and S-O, respectively.
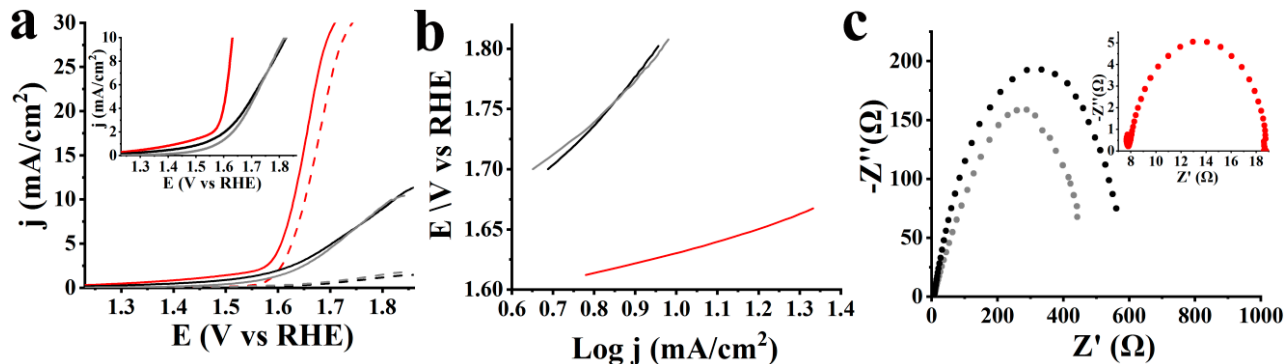

Figure 4. (a) LSVs, before (solid lines) and after 2000 cycles (dashed lines) for OER, (b) Tafel slopes, and (c) Nyquist plots of S-CNHs (red), ox-CNHs (black) and pristine CNHs (grey). Inset (a) LSVs at $10 \mathrm{~mA} / \mathrm{cm}^{2}$; (c) Nyquist plot for S-CNHs. The LSVs obtained at $1600 \mathrm{rpm}$ rotation speed and $5 \mathrm{mV} / \mathrm{s}$ scan rate.

Table 1. Electrochemical parameters for OER.

\begin{tabular}{|c|c|c|c|c|c|}
\hline Catalyst & $\begin{array}{c}\text { Potential (V vs. RHE) } \\
\text { at } 10 \mathrm{~mA} / \mathrm{cm}^{2}\end{array}$ & $\begin{array}{l}\text { Overpotential (mV vs. } \\
\text { RHE) at } 10 \mathrm{~mA} / \mathrm{cm}^{2}\end{array}$ & $\begin{array}{l}\text { Tafel Slope } \\
\text { (mV/dec) }\end{array}$ & $\begin{array}{l}\text { ECSA } \\
\left(\mathrm{cm}^{2}\right)^{b}\end{array}$ & $\mathbf{R}_{\mathrm{ct}}(\Omega)$ \\
\hline S-CNHs & 1.63 & 400 & 80 & 67.5 & 10.8 \\
\hline $\mathrm{S}-\mathrm{CNHs}{ }^{\mathrm{a}}$ & 1.65 & 420 & 84 & 61.25 & - \\
\hline ox-CNHs & 1.82 & 590 & 202 & 60 & 560.5 \\
\hline $\mathrm{ox}^{-\mathrm{CNHs}}{ }^{\mathrm{a}}$ & 2.5 & - & 279 & 13.75 & - \\
\hline pristine $\mathrm{CNHs}$ & 1.82 & 590 & 333 & 19.4 & 450.5 \\
\hline pristine CNHs ${ }^{a}$ & 2.5 & - & 310 & 4.7 & - \\
\hline
\end{tabular}

${ }^{a}$ After 2000 cycles. $^{b} \pm 2 \%$ error.

To define how swiftly the current increases with the applied overpotential, Tafel slopes were extracted from the LSV curves. Specifically, S-CNHs showed a low Tafel slope value of $80 \mathrm{mV} / \mathrm{dec}$, as shown in Figure $4 \mathrm{~b}$. Low Tafel slope values are required for ideal electrocatalysts as they result in an improved OER rate under a constant increase of overpotential, which can be beneficial in real applications. The two reference materials, ox-CNHs and pristine $\mathrm{CNHs}$, accordingly showed 
much higher Tafel slope values of 202 and $333 \mathrm{mV} / \mathrm{dec}$, which correspond to slower OER kinetics. Electrochemical impedance spectroscopy (EIS) assays were performed to evaluate the OER kinetics. $\mathrm{S}-\mathrm{CNHs}$ showed the smallest frequency semicircle in the Nyquist plot, which corresponds to a small charge transfer resistance $\left(\mathrm{R}_{\mathrm{ct}}\right)$ value of $10.8 \Omega$ (Figure $\left.4 \mathrm{c}\right)$. On the contrary, the very high $\mathrm{R}_{\mathrm{ct}}$ values of the ox-CNHs and pristine $\mathrm{CNHs}, 560.5$ and $450.5 \Omega$, respectively, reveal high charge transfer resistance. The higher $\mathrm{R}_{\mathrm{ct}}$ value of ox-CNHs compared to pristine CNHs is justified by the disruption of the graphitic network due to the introduction of carboxylic species. Conversely, the low charge transfer resistance that was reported for S-CNHs arises from the increased conductivity due to the improvement of the graphitic degree resulting from the sulfur doping.

Stability is a crucial factor for the evaluation of the overall performance of an electrocatalyst. Figure 4a shows the LSV polarization curves for OER of S-CNHs as compared to that for ox-CNHs and pristine CNHs, after continuous cycling for 2000 cycles. Notably, negligible loss of the anodic current is noted for S-CNHs. As a striking difference, the two reference materials exhibit extremely huge losses of the anodic current that are unable to reach current density values at $10 \mathrm{~mA} / \mathrm{cm}^{2}$. Electrochemical OER data for S-CNHs, ox-CNHs and pristine CNHs before and after 2000 cycles are summarized in Table 1.

To get a better understanding of the charge transport flow in S-CNHs in OER, the electrochemically active surface area (ECSA) was estimated. In more detail, ECSA values were calculated based on the following equation [20,33-36]: ECSA $=C_{d l} / C_{S}$, where $C_{d l}$ stands for the electrochemical double-layer capacitance, while $C_{S}$ is the specific capacitance of a flat surface with $1 \mathrm{~cm}^{2}$ of real surface area with a value assumed to be $40 \mu \mathrm{F} / \mathrm{cm}^{2}$ for the flat electrode. For the estimation of the ECSA, cyclic voltamographs were recorded in a non-Faradaic region at scan rates of 50, 100, 200, 300, 400 and $500 \mathrm{mV} / \mathrm{sec}$ for all tested materials before and after 2000 cycles (Figure 5). ECSA values were obtained from $C_{d l}$ by plotting the $\Delta j=\left(j_{a}-j_{c}\right)$ at a given potential versus the scan rate as stated in the equation $C_{d l}=d(\Delta j) / 2 d V_{b}$. Specifically, S-CNHs showed higher ECSA value of $\sim 67.5 \mathrm{~cm}^{2}$. Consistent with the LSV polarization curves for OER, ox-CNHs and pristine CNHs present significantly lower ECSA, ca. $\sim 60$ and $\sim 19.4 \mathrm{~cm}^{2}$, respectively. These values are in accordance with the electrocatalytic results towards OER, since the efficient accessibility of the active sites is related to higher ECSA values. Moreover, after cycling continuously for 2000 cycles, a slight decrease of the ECSA was noted for S-CNHs, $\sim 61.25 \mathrm{~cm}^{2}$, while ox-CNHs and pristine CNHs exhibited huge drops at $\sim 13.75$ and $\sim 4.7 \mathrm{~cm}^{2}$, respectively.

Next, the electrochemical properties of S-CNHs against HER were evaluated by performing LSV measurements in $\mathrm{N}_{2}$-saturated $0.5 \mathrm{M}$ aqueous $\mathrm{H}_{2} \mathrm{SO}_{4}$. The polarization curves of S-CNHs, along with ox-CNHs and pristine $\mathrm{CNHs}$ as well as commercially available $20 \mathrm{wt} \% \mathrm{Pt}$ on carbon black $(\mathrm{Pt} / \mathrm{C})$ as reference materials, can be seen in Figure 6a. The lowest onset potential is registered at $-0.2 \mathrm{~V}$ vs. RHE for S-CNHs, which is more positive by 50 and $120 \mathrm{mV}$ in comparison with the values noted for ox-CNHs (i.e., at $-0.25 \mathrm{~V}$ ) and pristine $\mathrm{CNHs}$ (i.e., at $-0.32 \mathrm{~V}$ ), respectively. In addition, potential values for HER are often compared at the functional current density for electrochemical water splitting of $-10 \mathrm{~mA} / \mathrm{cm}^{2}$, where sufficient hydrogen production is achieved, while faulty interpretations from intrinsic electroactivity are prevented. It is clear that S-CNHs show higher electrocatalytic activity at $-0.31 \mathrm{~V}$ vs. RHE, shifted by 120 and $440 \mathrm{mV}$ to more positive potentials compared to the value recorded for ox-CNHs (i.e., at $-0.43 \mathrm{~V}$ ) and pristine $\mathrm{CNHs}$ (i.e., at $-0.75 \mathrm{~V}$ ), respectively.

Furthermore, to define the rate-limiting step of HER, Tafel slopes were extracted from the LSV curves (Figure 6b). Additional analysis reveals that S-CNHs present a Tafel slope of $82 \mathrm{mV} / \mathrm{dec}$, which is slightly higher than the one of $\mathrm{Pt} / \mathrm{C}$ (i.e., $35 \mathrm{mV} / \mathrm{dec}$ ). The latter demonstrates that the electrochemical desorption of adsorbed hydrogen atoms onto the electrode (Heyrovsky desorption) is the rate-limiting step for HER. On the other hand, HER of ox-CNHs and pristine CNHs is rate-limited by the initial adsorption of a proton onto electrode's surface (Volmer adsorption), which is screened by the much higher Tafel slope values of 240 and $320 \mathrm{mV} / \mathrm{dec}$, respectively. The easier kinetics of HER, revealed from the much lower Tafel slope for S-CNHs, signifies more reactive/accessible protons and water molecules that reach the electrochemical active sites [33]. 

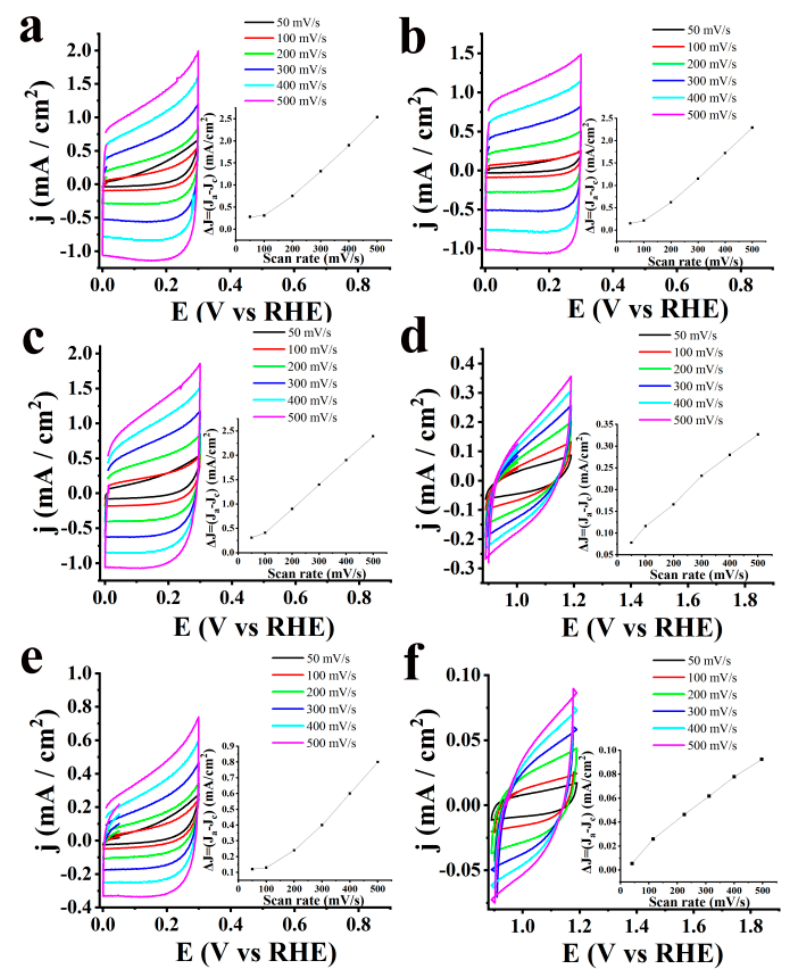

Figure 5. Cyclic voltamographs for OER of S-CNHs (a) before and (b) after 2000 cycles, ox-CNHs (c) before and (d) after 2000 cycles and pristine CNHs (e) before and (f) after 2000 cycles measured in a nitrogen saturated aqueous $1.0 \mathrm{M} \mathrm{KOH}$, at a rotation speed of $1600 \mathrm{rpm}$ and scan rates from 50 to $500 \mathrm{mV} / \mathrm{s}$. Inset: Scan rate dependence of the current densities for the corresponding materials.
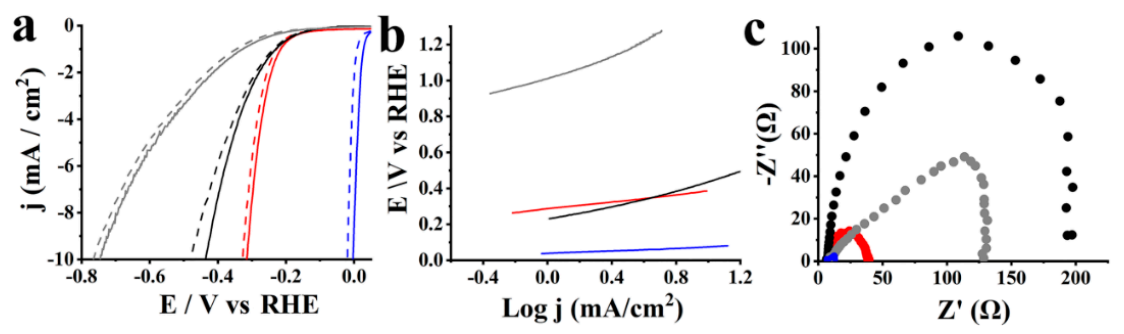

Figure 6. (a) LSVs, before (solid lines) and after 10,000 cycles (dashed lines) for HER, (b) Tafel slopes, and (c) Nyquist plots of S-CNHs (red), ox-CNHs (black), pristine CNHs (grey) and Pt/C (blue). The LSV polarization curves obtained at $1600 \mathrm{rpm}$ rotation speed and $5 \mathrm{mV} / \mathrm{s}$ scan rate.

Next, EIS assays were performed to evaluate the HER kinetics. EIS measurements further confirm the superior HER kinetics of S-CNHs (Figure $6 c$ ), which show the smallest $\mathrm{R}_{\mathrm{ct}}$ value of $30.4 \Omega$, comparable to that of $\mathrm{Pt} / \mathrm{C}$ (i.e., $6.1 \Omega$ ). On the other hand, ox-CNHs and pristine $\mathrm{CNHs}$ exhibited much higher $R_{c t}$ values, 197 and $123.4 \Omega$, respectively. This tendency is in line with the results of Tafel slope values, which reveal improved kinetics and higher electrocatalyst activity of S-CNHs.

Additionally, the long-term stability of S-CNHs was assessed on the basis of durability studies. Figure 6a shows the LSV polarization curves for HER of S-CNHs in comparison to that for ox-CNHs, pristine $\mathrm{CNH}$ and $\mathrm{Pt} / \mathrm{C}$, after ongoing cycling for 10,000 cycles, where negligible loss of the cathodic current is noted. Table 2 summarizes the HER-derived data for all tested materials, before and after 10,000 cycles. Finally, the ECSA values were also calculated. Cyclic voltamographs for HER of S-CNHs, as compared to that for ox-CNHs, pristine $\mathrm{CNHs}$ and $\mathrm{Pt} / \mathrm{C}$, in a non-Faradaic region were measured at scan rates of 50, 100, 200, 300, 400 and $500 \mathrm{mV} / \mathrm{sec}$ (Figure 7). Particularly, S-CNHs exhibit the higher ECSA value, $\sim 205 \mathrm{~cm}^{2}$, while the equivalent values that are noted for ox-CNHs and pristine CNHs are 
significantly lower, i.e., $\sim 130$ and $\sim 31.25 \mathrm{~cm}^{2}$, respectively. Similarly, the estimated ECSA values for the same materials after 10,000 cycles are remarkably lower than that recorded for S-CNHs.

Table 2. Electrochemical parameters for HER.

\begin{tabular}{|c|c|c|c|c|c|}
\hline Catalyst & $\begin{array}{l}\text { Onset Potential } \\
\text { (V vs. RHE) }\end{array}$ & $\begin{array}{l}\text { Potential (V vs. RHE) } \\
\text { at }-10 \mathrm{~mA} / \mathrm{cm}^{2}\end{array}$ & $\begin{array}{l}\text { Tafel Slope } \\
\text { (mV/dec) }\end{array}$ & $\begin{array}{l}\text { ECSA } \\
\left(\mathrm{cm}^{2}\right)^{b}\end{array}$ & $\mathbf{R}_{\mathrm{ct}}(\Omega)$ \\
\hline $\mathrm{S}-\mathrm{CNHs}$ & -0.2 & -0.29 & 82 & 205 & 30.4 \\
\hline $\mathrm{S}-\mathrm{CNH} \mathrm{s}^{\mathrm{a}}$ & -0.21 & -0.33 & 82 & 190 & - \\
\hline ox-CNHs & -0.25 & -0.43 & 240 & 130 & 197 \\
\hline $\mathrm{ox}_{-\mathrm{CNHs}}{ }^{\mathrm{a}}$ & -0.26 & -0.48 & 245 & 102 & - \\
\hline pristine $\mathrm{CNHs}$ & -0.34 & -0.75 & 320 & 47.5 & 123.4 \\
\hline pristine $\mathrm{CNHs}^{\mathrm{a}}$ & -0.35 & -0.79 & 320 & 31.25 & - \\
\hline $\mathrm{Pt} / \mathrm{C}$ & 0.034 & -0.0025 & 35 & 364 & 6.1 \\
\hline $\mathrm{Pt} / \mathrm{C}^{\mathrm{a}}$ & 0.011 & -0.02 & 35 & 350 & - \\
\hline
\end{tabular}

${ }^{a}$ After 10,000 cycles. ${ }^{b} \pm 2 \%$ error.
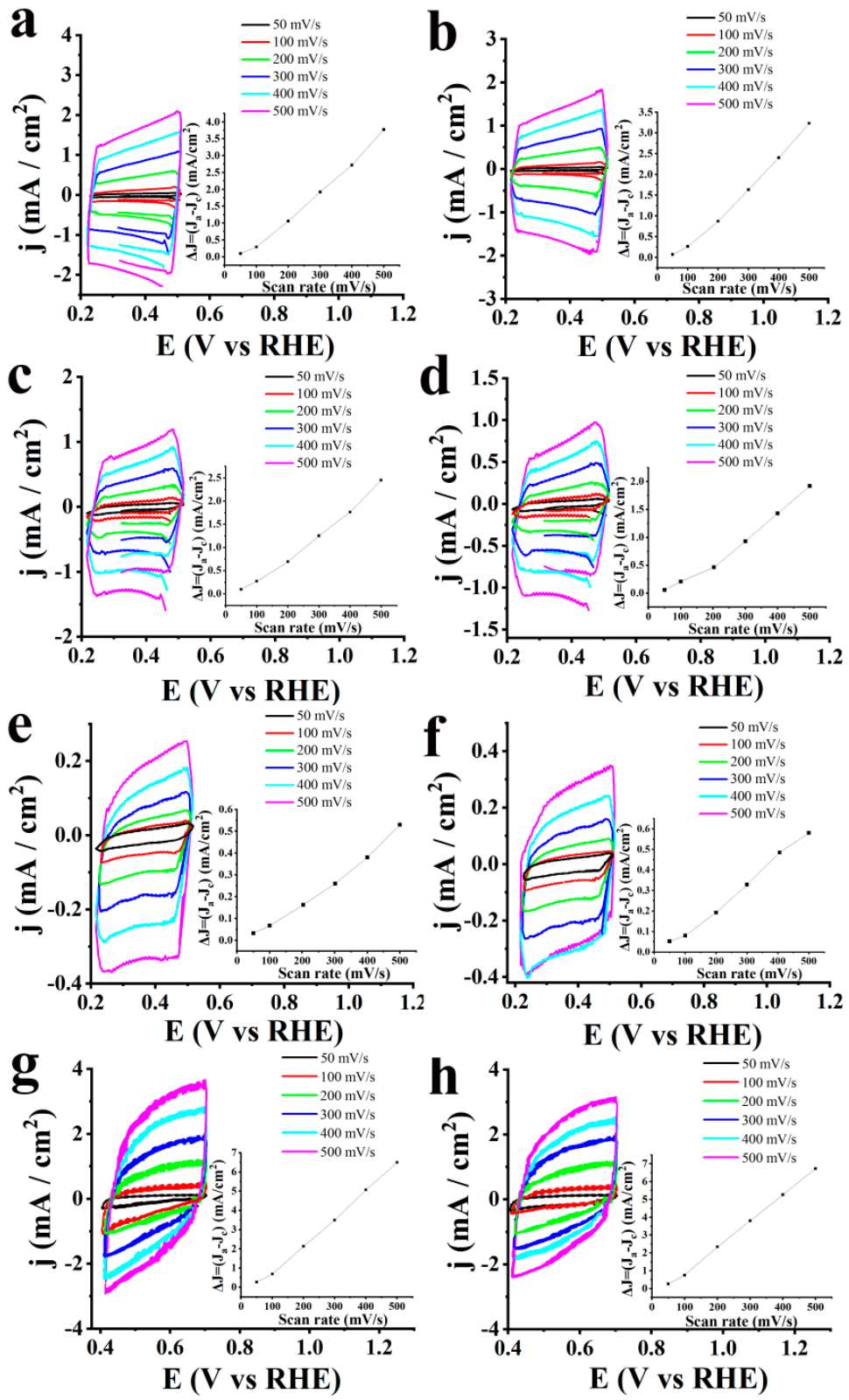

Figure 7. Cyclic voltamographs for HER of S-CNHs (a) before, and (b) after 10,000 cycles, ox-CNHs (c) before, and (d) after 10,000 cycles, pristine CNHs (e) before, and (f) after 10,000 cycles, and Pt/C (g) before, 
and (h) after 10,000 cycles, measured in a nitrogen saturated aqueous $0.5 \mathrm{M} \mathrm{H}_{2} \mathrm{SO}_{4}$ electrolyte, at a rotation speed of $1600 \mathrm{rpm}$ and scan rates from 50 to $500 \mathrm{mV} / \mathrm{s}$. Inset: Scan rate dependence of the current densities for the corresponding materials.

\section{Conclusions}

In summary, we used a facile doping strategy to introduce sulfur atoms into the graphitic network of CNHs, and we tested S-CNHs against OER and HER. The S-CNHs proved to be a highly efficient bifunctional electrocatalyst towards water splitting due to the high $S$ doping levels. Doping with sulfur effectively modified the electronic structure of CNHs, which along with high conductivity helped to achieve low overpotential values for both OER and HER. Specifically, S-CNHs showed low overpotential for oxygen and hydrogen evolution reaction, at 1.63 and $-0.2 \mathrm{~V}$ vs. RHE, respectively, and excellent durability and stability. Additionally, S-CNHs exhibited significantly lower Tafel slope and lower current resistance compared to oxidized and pristine CNHs for both electrocatalytic reactions. The easy preparation method, high activity and excellent durability of S-CNHs make them a promising alternative for replacing noble-metal-based electrocatalysts for water splitting.

Author Contributions: Conceptualization, A.K. and N.T.; validation, A.K. and N.T.; investigation, A.K. and N.T.; TEM imaging, R.A.; writing-original draft preparation, A.K. and N.T.; writing-review and editing, A.K., R.A. and N.T.; visualization, A.K., R.A. and N.T.; project administration, A.K. and N.T.; funding acquisition, A.K. and R.A. All authors have read and agreed to the published version of the manuscript.

Funding: This research is co-financed by Greece and the European Union (European Social Fund) through the Operational Programme "Human Resources Development, Education and Lifelong Learning" in the context of the project "Reinforcement of Postdoctoral Researchers-2nd Cycle" (MIS 5033021), implemented by the State Scholarships Foundation (IK $\Upsilon$ ). R.A. gratefully acknowledges the support from the Spanish Ministry of Economy and Competitiveness (MINECO) and the MICINN through project grants MAT2016-79776-P (AEI/FEDER, UE) and PID2019-104739GB-I00/AEI/10.13039/501100011033 as well as from the European Union H2020 program “ESTEEM3" (823717) and Flag-ERA GATES (JTC-PCI2018-093137).

Acknowledgments: HRTEM and XPS were conducted at the Laboratorio de Microscopias Avanzadas (LMA), Universidad de Zaragoza, Spain. We thank G. Antorrena (LMA) for the XPS acquisition.

Conflicts of Interest: The authors declare no conflict of interest.

\section{References}

1. Song, J.; Wie, C.; Huang, Z.-F.; Liu, C.; Zeng, L.; Wang, X.; Xu, Z.J. A review on fundamentals for designing oxygen evolution electrocatalysts. Chem. Soc. Rev. 2020, 49, 2196-2214. [CrossRef] [PubMed]

2. Tahir, M.; Pan, L.; Idrees, F.; Zhang, X.; Wang, L.; Zou, J.-J.; Wang, Z.L. Electrocatalytic oxygen evolution reaction for energy conversion and storage: A comprehensive review. Nano Energy 2017, 37, 136-157. [CrossRef]

3. Wei, C.; Rao, R.R.; Peng, J.; Huang, B.; Stephens, I.E.L.; Risch, M.; Xu, Z.J.; Shao-Horn, Y. Recommended practices and benchmark activity for hydrogen and oxygen electrocatalysis in water splitting and fuel cells. Adv. Mater. 2019, 31, 1806296. [CrossRef] [PubMed]

4. $\quad$ Gloag, L.; Benedetti, T.M.; Cheong, S.; Li, Y.; Chan, X.-H.; Lacroix, L.-M.; Chang, S.L.Y.; Arenal, R.; Florea, I.; Barron, H.; et al. Three-dimensional branched and faceted gold-ruthenium nanoparticles: Using nanostructure to improve stability in oxygen evolution electrocatalysis. Angew. Chem. Int. Ed. 2018, 57, 10241-10245. [CrossRef] [PubMed]

5. Kagkoura, A.; Canton-Vitoria, R.; Vallan, L.; Hernandez-Ferrer, J.; Benito, A.M.; Maser, W.K.; Arenal, R.; Tagmatarchis, N. Bottom-up synthesized $\mathrm{MoS}_{2}$ interfacing polymer carbon nanodots with electrocatalytic activity for hydrogen evolution. Chem. Eur. J. 2020, 26, 6635-6642. [CrossRef]

6. Kagkoura, A.; Tzanidis, I.; Dracopoulos, V.; Tagmatarchis, N.; Tasis, D. Template synthesis of defect-rich $\mathrm{MoS}_{2}$-based assemblies as electrocatalytic platforms for hydrogen evolution reaction. Chem. Commun. 2019, 55, 2078-2081. [CrossRef]

7. Zhang, W.; Liao, X.; Pan, X.; Yan, M.; Li, Y.; Tian, X.; Zhao, Y.; Xu, L.; Mai, L. Superior hydrogen evolution reaction performance in $2 \mathrm{H}-\mathrm{MoS}_{2}$ to that of $1 \mathrm{~T}$ phase. Small 2019, 15, 1900964. [CrossRef] 
8. Jia, X.; Ren, H.; Hu, H.; Song, Y.-F. 3D Carbon foam supported edge-rich N-doped $\mathrm{MoS}_{2}$ nanoflakes for enhanced electrocatalytic hydrogen evolution. Chem. Eur. J. 2020, 26, 4150-4156. [CrossRef]

9. Yi, X.; He, X.; Yin, F.; Chen, B.; Li, G.; Yin, H. One-step synthesis of oxygen incorporated V-MoS 2 supported on partially sulfurized nickel foam as a highly active catalyst for hydrogen evolution. Int. J. Hydrogen Energy 2020, 45, 2774-2784. [CrossRef]

10. Bolar, S.; Shit, S.; Kumar, J.S.; Murmu, N.C.; Ganesh, R.S.; Inokawa, H.; Kuila, T. Optimization of active surface area of flower like $\mathrm{MoS}_{2}$ using V-doping towards enhanced hydrogen evolution reaction in acidic and basic medium. Appl. Catal. B 2019, 254, 432-442. [CrossRef]

11. Mohanty, B.; Ghorbani-Asl, M.; Kretschmer, S.; Ghosh, A.; Guha, P.; Panda, S.K.; Jena, B.; Krasheninnikov, A.V.; Jena, B.K. $\mathrm{MoS}_{2}$ Quantum dots as efficient catalyst materials for the oxygen evolution reaction. ACS Catal. 2018, 8, 1683-1689. [CrossRef]

12. Badruzzaman, A.; Yuda, A.; Ashock, A.; Kumar, A. Recent advances in cobalt based heterogeneous catalysts for oxygen evolution reaction. Inorg. Chim. Acta 2020, 511, 119854. [CrossRef]

13. Tang, B.; Yu, Z.G.; Seng, H.L.; Zhang, N.; Liu, X.; Zhang, Y.-W.; Yang, W.; Gong, H. Simultaneous edge and electronic control of $\mathrm{MoS}_{2}$ nanosheets through Fe doping for an efficient oxygen evolution reaction. Nanoscale 2018, 10, 20113-20119. [CrossRef] [PubMed]

14. Xu, Y.; Tu, W.; Zhang, B.; Yin, S.; Huang, Y.; Kraft, M.; Xu, R. Nickel nanoparticles encapsulated in few-layer nitrogen-doped graphene derived from metal-organic frameworks as efficient bifunctional electrocatalysts for overall water splitting. Adv. Mater. 2017, 29, 1605957. [CrossRef]

15. Kagkoura, A.; Tagmatarchis, N. Carbon nanohorn-based electrocatalysts for energy conversion. Nanomaterials 2020, 10, 1407. [CrossRef] [PubMed]

16. Karousis, N.; Suarez-Martinez, I.; Ewels, C.P.; Tagmatarchis, N. Structure, properties, functionalization, and applications of carbon nanohorns. Chem. Rev. 2016, 116, 4850-4883. [CrossRef]

17. Pippa, N.; Stangel, C.; Kastanas, I.; Triantafyllopoulou, E.; Naziris, N.; Stellas, D.; Zhang, M.; Yudasaka, M.; Demetzos, C.; Tagmatarchis, N. Carbon nanohorn/liposome systems: Preformulation, design and in vitro toxicity studies. Mater. Sci. Eng. C 2019, 105, 110114. [CrossRef]

18. Stergiou, A.; Perivoliotis, D.K.; Tagmatarchis, N. (Photo)electrocatalysis of molecular oxygen reduction by S-doped graphene decorated with a star-shaped oligothiophene. Nanoscale 2019, 11, 7335-7346. [CrossRef]

19. Dumont, J.H.; Martinez, U.; Artyushkova, K.; Purdy, G.M.; Dattelbaum, A.M.; Zelenay, P.; Mohite, A.; Atanassov, P.; Gupta, G. Nitrogen-doped graphene oxide electrocatalysts for the oxygen reduction reaction. ACS Appl. Nano Mater. 2019, 2, 1675-1682. [CrossRef]

20. Kagkoura, A.; Pelaez-Fernandez, M.; Arenal, R.; Tagmatarchis, N. Sulfur-doped graphene/transition metal dichalcogenide heterostructured hybrids with electrocatalytic activity toward the hydrogen evolution reaction. Nanoscale Adv. 2019, 1, 1489-1496. [CrossRef]

21. Perivoliotis, D.K.; Sato, Y.; Suenaga, K.; Tagmatarchis, N. Sulfur-doped graphene-supported nickel-core palladium-shell nanoparticles as efficient oxygen reduction and methanol oxidation electrocatalyst. ACS Appl. Energy Mater. 2018, 1, 3869-3880. [CrossRef]

22. Wu, X.; Cui, L.; Tang, P.; Hu, Z.; Ma, D.; Shi, Z. Synthesis and catalytic activity of heteroatom doped metal-free single-wall carbon nanohorns. Chem. Commun. 2016, 52, 5391-5393. [CrossRef] [PubMed]

23. Wee, J.H.; Kim, C.H.; Lee, H.S.; Choi, G.B.; Kim, D.W.; Yang, C.M.; Kim, Y.A. Enriched pyridinic nitrogen atoms at nanoholes of carbon nanohorns for efficient oxygen reduction. Sci. Rep. 2019, 9, 20170. [CrossRef] [PubMed]

24. Wu, X.; Liu, L.; Tang, P.; Li, M.; Shi, Z. Influence of nitrogen precursors on the structure, composition, and oxygen reduction reaction performance of dual heteroatom doped carbon nanohorns. RSC Adv. 2016, 6, 63730-63735. [CrossRef]

25. Tan, X.; Zhang, J.; Wu, X.; Wang, Y.; Li, M.; Shi, Z. Palladium nanoparticles loaded on nitrogen and boron dual-doped single-wall carbon nanohorns with high electrocatalytic activity in the oxygen reduction reaction. RSC Adv. 2018, 8, 33688-33694. [CrossRef]

26. Maciasa, E.M.; Valenzuela-Muñiz, A.M.; Alonso-Núñez, G.; Farías Sánchez, M.H.; Gauvinc, R.; Gómez, Y.V. Sulfur doped carbon nanohorns towards oxygen reduction reaction. Diam. Relat. Mater. 2020, 103, 107671. [CrossRef] 
27. Unni, S.M.; Bhange, S.N.; Illathvalappil, R.; Mutneja, N.; Patil, K.R.; Kurungot, R. Nitrogen-induced surface area and conductivity modulation of carbon nanohorn and its function as an efficient metal-free oxygen reduction electrocatalyst for anion-exchange membrane fuel cells. Small 2015, 11, 352-360. [CrossRef]

28. Devadas, B.; Imae, T. Hydrogen evolution reaction efficiency by low loading of platinum nanoparticles protected by dendrimers on carbon materials. Electrochem. Commun. 2016, 72, 135-139. [CrossRef]

29. Devadas, B.; Chang, C.C.; Imae, T. Hydrogen evolution reaction efficiency of carbon nanohorn incorporating molybdenum sulfide and polydopamine/palladium nanoparticles. Taiwan Inst. Chem. Eng. 2019, 102, 378-386. [CrossRef]

30. Guo, Y.; Zhou, Y.; Nan, Y.; Li, B.; Song, X. Ni-Based nanoparticle-embedded N-doped carbon nanohorns derived from double core-shell CNH@PDA@NiMOFs for oxygen electrocatalysis. ACS Appl. Mater. Interfaces 2020, 12, 12743-12754. [CrossRef]

31. Yang, S.; Zhi, L.; Tang, K.; Feng, X.; Maier, J.; Müllen, K. Efficient synthesis of heteroatom (N or S)-doped graphene based on ultrathin graphene oxide-porous silica sheets for oxygen reduction reactions. Adv. Funct. Mater. 2012, 22, 3634-3640. [CrossRef]

32. Herrmann, I.; Kramm, U.I.; Radnik, J.S.; Fiechter, S.; Bogdanoff, P. Influence of sulfur on the pyrolysis of CoTMPP as electrocatalyst for the oxygen reduction reaction. J. Electrochem. 2009, 156, B1283-B1292. [CrossRef]

33. Chen, Y.; Yang, K.; Jiang, B.; Li, J.; Zeng, M.; Fu, L. Emerging two-dimensional nanomaterials for electrochemical hydrogen evolution. J. Mater. Chem. A 2017, 5, 8187-8208. [CrossRef]

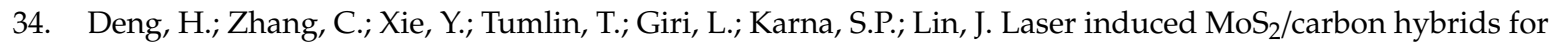
hydrogen evolution reaction catalysts. J. Mater. Chem. A 2016, 4, 6824-6830. [CrossRef]

35. You, B.; Jiang, N.; Sheng, M.; Bhushan, M.W.; Sun, Y. Hierarchically Porous Urchin-like Ni2P Superstructures Supported on Nickel Foam as Efficient Bifunctional Electrocatalysts for Overall Water Splitting. ACS Catal. 2016, 6, 714-721. [CrossRef]

36. Lu, X.; Zhao, C. Electrodeposition of hierarchically structured three-dimensional nickel-iron electrodes for efficient oxygen evolution at high current densities. Nat. Commun. 2015, 6, 6616. [CrossRef]

Publisher's Note: MDPI stays neutral with regard to jurisdictional claims in published maps and institutional affiliations.

(C) 2020 by the authors. Licensee MDPI, Basel, Switzerland. This article is an open access article distributed under the terms and conditions of the Creative Commons Attribution (CC BY) license (http://creativecommons.org/licenses/by/4.0/). 